\title{
El abrigo de Martinarri (Obécuri, Treviño): una ocupación del Tardiglaciar en la Cuenca Alta del Ebro
}

\author{
Martinarri rock shelter (Obécuri, Treviño): a Late Glacial occupation of the Upper \\ Basin of the Ebro
}

\author{
Alfonso Alday (*) \\ Adriana Soto (*) \\ Judit López de Heredia (*) \\ Unai Perales (*)
}

\section{RESUMEN}

Presentamos el yacimiento de Martinarri, recientemente descubierto en Treviño. Los iniciales trabajos de excavación han evidenciado ocupaciones en el tránsito del Pleistoceno al Holoceno que llenan de contenido un episodio cultural muy desconocido en el Alto Ebro, en particular, y en el interior de la Península Ibérica, en general. En el texto se ofrece una primera evaluación tanto de la secuencia estratigráfica como de los materiales recuperados, esbozando junto con los datos radiocronológicos (inéditos), una primera interpretación de la dinámica ocupacional del lugar. Dada la propia naturaleza del período se revisa el conocimiento disponible en la actualidad sobre el mismo y se reflexiona sobre su caracterización.

\begin{abstract}
We present recently discovered Martinarri's site, in Treviño. The initial excavations have shown that it was occupied during the transition from Pleistocene to Holocene, providing information of a largely unknown episode in the Upper Ebro and in the interior of the Iberian peninsula. The text provides an initial assessment of the stratigraphic sequence and the materials recovered. Along with carbon-14 data (unpublished), we propose an initial interpretation of the dynamics of occupation of the site. Also, the nature of the period to which it refers, requires a review of currently available knowledge and reflection on its characterization.
\end{abstract}

(*) Área de Prehistoria, Universidad del País Vasco. C/ Tomás y Valiente s/n. 01006 Vitoria-Gasteiz. Álava.

Correos e.: a.alday@ehu.es; asoto.sebastian@yahoo.es;

jlzdeheredia@gmail.com; perales.unai@gmail.com

Recibido: 20-X-2011; aceptado: 28-XII-2011.
Palabras clave: Tardiglaciar; Aziliense; Mesolítico; Sauveterriense; C14; Alto Ebro.

Key words: Late Glacial; Azilian; Mesolithic; Sauveterriense; C14; Upper Ebro.

\section{INTRODUCCIÓN}

Las dos últimas décadas han conocido un progresivo aumento del conocimiento de los grupos mesolíticos en la Alta Cuenca del Ebro, gracias al incremento del número de yacimientos con secuencias estratigráficas, de los registros materiales y de fauna y de las series polínicas que fijan los paisajes. Así se ha reconocido la evolución crono-cultural del período y caracterizado sus vectores de poblamiento y de economía (Cava et al. 2009).

Pero el Tardiglaciar y los inicios del Holoceno siguen siendo aún épocas poco conocidas. Ello refuerza el interés de los conjuntos arqueológicos que se vienen documentando en fechas recientes. Este es el contexto del descubrimiento y primeras actuaciones realizadas en el abrigo de Martinarri (Obécuri, Treviño) que presentamos.

\section{DESCUBRIMIENTO DEL YACIMIENTO}

El descubrimiento de Martinarri se inserta en un proyecto de prospecciones iniciado en 1990, centrado en la identificación de ocupaciones me- 
solíticas y neolíticas en el Condado de Treviño (Fig. 1). En este contexto se enmarcan los trabajos de excavación y posterior divulgación del túmulo de San Quílez (San Martín Zar) y del abrigo de Mendandia (Sáseta), así como los sondeos practicados en los abrigos de Ajarte. Estas actividades han reunido información relevante para la localización de cavidades y abrigos, tanto geológica como toponímica y etnográfica.

Este fue el caso del abrigo de Martinarri, topónimo que identifica un área boscosa colindante al actual campo de golf de Izki (Urturi, Álava), y que nos interesó por su posible potencial arqueológico. Nos hicieron falta tres salidas al campo, en varios años, para concretar la situación del término y del abrigo. En las dos primeras se avistaron pequeños refugios que no nos parecieron aptos para su ocupación en épocas prehistóricas. En la tercera, planificada el 12 de marzo del 2007, acompañados por la guarda forestal de la comarca, localizamos el abrigo, así como otro más, donde se recogieron algunos elementos líticos en superficie.

$\mathrm{Su}$ situación, en el interior de un denso robledal apartado de pistas forestales, impide su visualización hasta no hallarse en su proximidad. Por ello ha pasado desapercibido y sin mención en la literatura arqueológica. El acceso al yacimiento no resulta dificultoso, una vez conocido su em- plazamiento (coordenadas UTM 30N Y4723191X538840).

\section{EL YACIMIENTO Y SU CONTEXTO}

El abrigo está orientado al sur, con una techumbre que se eleva casi $3 \mathrm{~m}$ sobre el suelo actual. Cobija una superficie de unos $15 \mathrm{~m}$ de longitud por 3-4 $\mathrm{m}$ de profundidad, amplia para lo habitual en la documentación arqueológica de la zona. Probablemente su imagen actual no difiere de la prehistórica: no hay aparentemente derrumbes o alteraciones que hayan mermado su integridad. Ofrece un adecuado cobijo a un grupo de pequeño-medio tamaño que puede ocupar también la amplísima terraza que antecede al abrigo (Fig. 2).

Martinarri comparte los caracteres geoecológicos del Parque Natural de Izki (Álava), del que está excluido por cuestiones administrativas. La comarca es una amplia cubeta encajada entre diversos cordales calcáreos y cubierta por un denso manto forestal. Durante el Campaniense se formó un vasto terreno ondulado de arenas y gravas, donde lo excepcional son los pequeños afloramientos de arenisca a manera de abrigos. Entre los que conocemos, Martinarri reúne las mejores

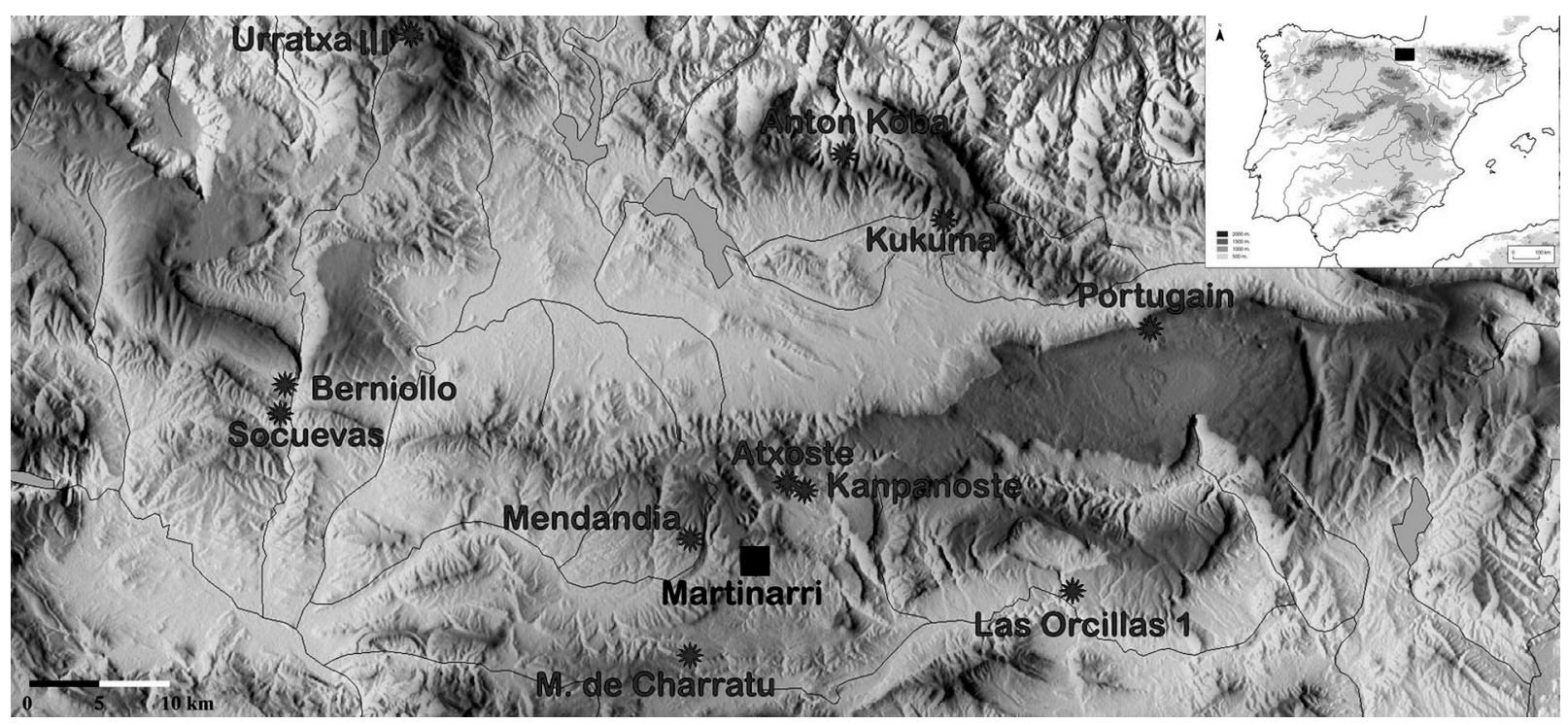

Fig. 1. Situación geográfica de Martinarri (Obécuri, Condado de Treviño) y de los yacimientos contemporáneos más próximos.

Trab. Prehist., 69, N. ${ }^{\text {2 }}$, julio-diciembre 2012, pp. 257-272, ISSN: 0082-5638

doi: $10.3989 /$ tp.2012.12091 

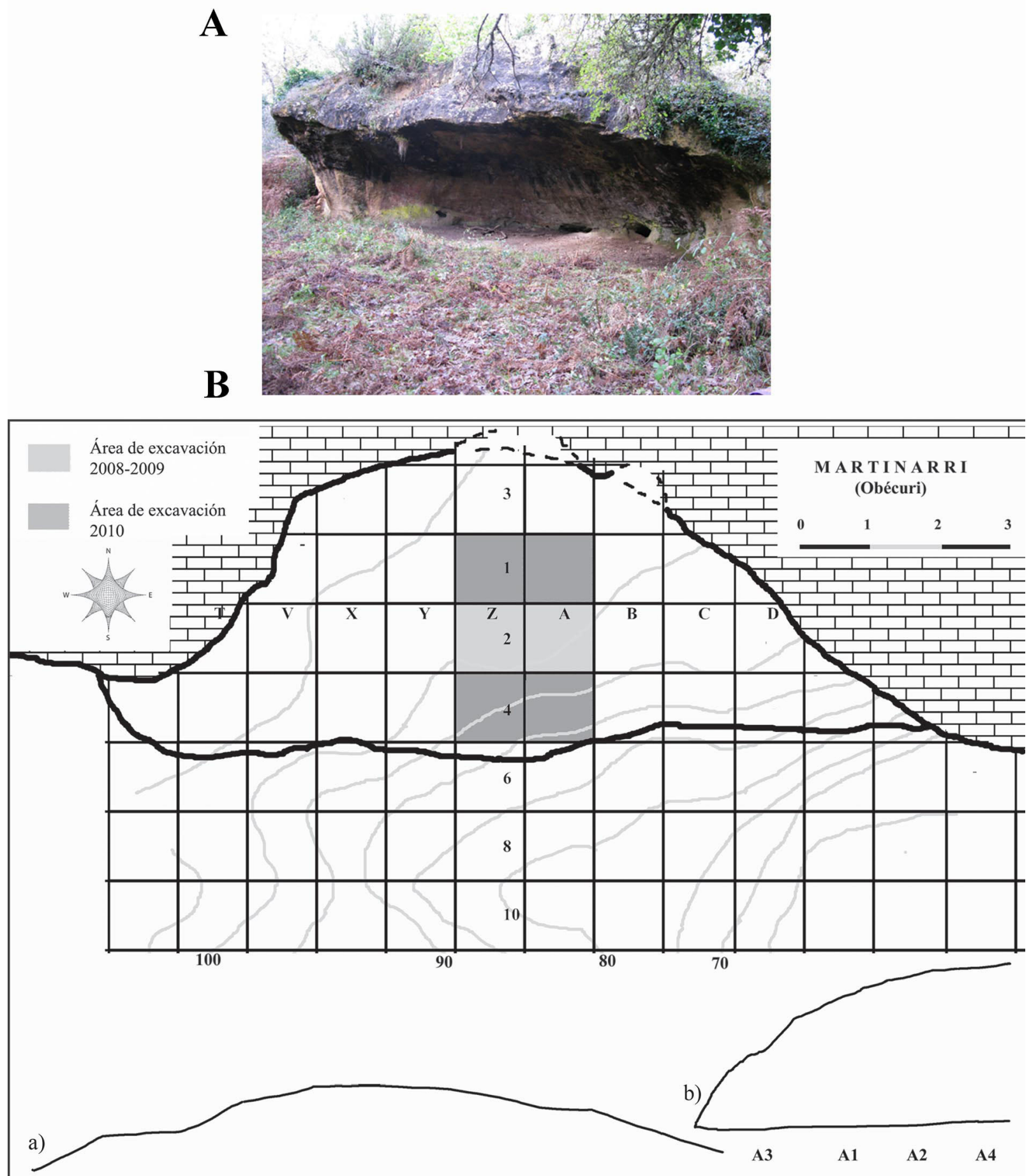

Fig. 2. Abrigo de Martinarri (Obécuri, Condado de Treviño). A. Vista general del abrigo antes de su excavación; B. Plano del área de excavación y secciones a) frontal y b) sagital. 
condiciones de habitabilidad. Este hecho nos hace reflexionar sobre el buen conocimiento espacial que tenían las comunidades prehistóricas locales. $\mathrm{Su}$ capacidad de orientación, en una topografía poco relevante, indica un experimentado control del territorio que, con seguridad, va más allá del mero asentamiento temporal en el abrigo.

La característica actual del entorno es su densidad forestal. Domina el Quercus pirenaica (roble marojo, o roble basto o almez) junto a especies acidófilas como el acebo, el brezo y los helechos, que ceden su empuje a los hayedos en las áreas más húmedas. La diversidad paisajística debió favorecer la convivencia de distintos mamíferos, cazados por los grupos prehistóricos, si bien nos falta todavía la lectura de los restos faunísticos recuperados durante las excavaciones.

El territorio de captación del yacimiento (límite a las 2 horas de marcha) abarca unos 125 $\mathrm{km}^{2}$ : aproximadamente un tercio del que recorreríamos si el terreno fuera llano: lo habitual en otros campamentos del entorno (Alday 2005). Es un área caracterizada por las continuas lomas y barrancos (Arrugaza, Lucia, Luzarun, Escarrerana...), con el $60 \%$ del terreno entre los 700 y los $800 \mathrm{~m}$ de altitud, el $13 \%$ por debajo, el $22 \%$ entre 800 y $900 \mathrm{~m}$ de altitud y el $5 \%$ por encima. Acotado al Norte por unas elevaciones que lo separan del Valle de Arraia; al Sur por la Sierra de Cantabria; al Este por las lomas que deslindan Álava y Navarra y al Oeste por el barranco ArluceaMarquínez y el reborde oriental de la Cuenca del Ayuda (Fig. 1).

Casualidad o no, el área no comparte los rasgos más tipificados de los episodios mesolíticosneolíticos antiguos. Los altos de caza de esas épocas se caracterizan por la convergencia de biotopos con acceso hacia tierras de montaña y de valle, y sus estratégicas posiciones (Alday 2005). La cubeta donde se enclava Martinarri no encaja en esos rasgos. ¿Es acaso la razón de su abandono tras la primera fase mesolítica, cuando el modelo descrito se impone?

El terreno carece de un cauce fluvial de caudal regular (excepto en su límite sur donde discurre el Ega), pero cuenta con numerosos arroyos (el de Izki que nace en las inmediaciones de Martinarri y todos los que conforman los barrancos antes mencionados) y son habituales los trampales y las turberas.

El sílex, materia prima fundamental para las sociedades prehistóricas, encuentra sus aflora- mientos más cercanos a una veintena de kilómetros al oeste -variedades de Loza y de Treviño- o a una treintena al noroeste -variedad de Urba$\mathrm{sa}-$. Estas tres variantes silíceas, y otras de orígenes más alejados, se han reconocido como mayoritarias en Martinarri: esta circunstancia revela que la ocupación del abrigo se conjuga con otros elementos dentro de una estrategia global de explotación del medio.

\section{EL TRABAJO ARQUEOLÓGICO}

En la retirada de las tierras seguimos los protocolos metodológicos habituales para este tipo de yacimientos sin demasiada extensión y secuencias estratigráficas divisibles en pequeños tramos. El campamento se ha parcelado en unidades de $1 \mathrm{~m}^{2}$, a su vez subdivididos en 9 sectores regulares. El levantamiento de las capas es independiente por sector, en semitallas de un máximo de $5 \mathrm{~cm}$ de espesor que respetan la individualidad de los niveles. Las tierras se criban en seco con cedazos de malla fina, reservando una parte para recuperar macrorrestos vegetales mediante flotación.

Se han practicado 3 campañas de excavación (2008 a 2010) autorizadas por la Junta de Castilla y León. Las dos primeras buscaron reconocer la secuencia estratigráfica hasta las arenas de base de los cuadros A2 y Z2. La tercera ha ampliado el trabajo a los cuadros A4, Z4, A1 y Z1, sin completar su excavación. La subvención económica se limitó a alguna partida para kilometraje y carbono 14 sufragada por el Grupo de Investigación en Prehistoria del Departamento de Geografía, Prehistoria y Arqueología de la Universidad del País Vasco. Ello ha reducido el equipo y el habitual ritmo de trabajo. A las tres semanas de campo anuales se suman otras tres para la limpieza, primer tratamiento, sigla e inventario de la colección. El primer proceso es especialmente delicado dada la costra arenosa que suele recubrir los hallazgos. Según recomendación del Servicio de Restauración de la Diputación Foral de Álava, el material inorgánico se baña en una primera solución de agua con un $10 \%$ de ácido nítrico y en una segunda de agua con bicarbonato sódico.

Las estructuras sedimentarias se identifican con una numeración correlativa $(100,101,102 \ldots)$ para los niveles estratigráficos, mientras que las 
unidades estratigráficas específicas (UE1, UE2...) son integradas en sus correspondientes horizontes.

\section{LA SECUENCIA ESTRATIGRÁFICA Y EL MATERIAL ARQUEOLÓGICO}

Hemos individualizado cinco niveles (superficial, 100, 101, 102 y 103) y diversas unidades estratigráficas en el depósito de Martinarri. El suelo del abrigo mantiene desde sus inicios una superficie prácticamente horizontal cuyo componente natural básico son las arenas. Por los caracteres del sitio, no intervienen sobre los sedimentos ni arroyadas, ni movimientos de ladera que pudieran desmantelar los estratos, ni aumentar la sedimentación. Así las capas adoptan una posición tendida, superponiéndose sin buzamientos ni encabalgamientos. En suma, la secuencia debe conservar bastante bien la historia sedimentaria del lugar.
Las variaciones de textura, color y compacidad de arenas, areniscas y gravas de la matriz sedimentaria fundamentan la discriminación de horizontes. La superficie excavada queda protegida por la techumbre, salvo una pequeña área hacia el sur (de los cuadros A4 y Z4) expuesta a las precipitaciones. Aquí las especificaciones advertidas en los caracteres de las tierras no niegan la entidad de cada capa (Fig. 3).

Describimos brevemente cada unidad y contenido arqueológico del depósito de techo a base: Nivel superficial: es una débil capa de humus y arenas sueltas que, en los cuadros protegidos por la visera, tiene $3 \mathrm{~cm}$ de potencia. Incluye manchas carbonosas de apariencia reciente. En muchos sectores, un barrido y débil raspado permite recoger algunos materiales arqueológicos. En los cuadros exteriores, donde un manto herbáceo cubre la superficie, las tierras son marrones oscuras con muchas raíces y, ocasionalmente, carbones de hogueras recientes. En un segundo rebaje, el sedimento abandona su componente vegetal y ad-

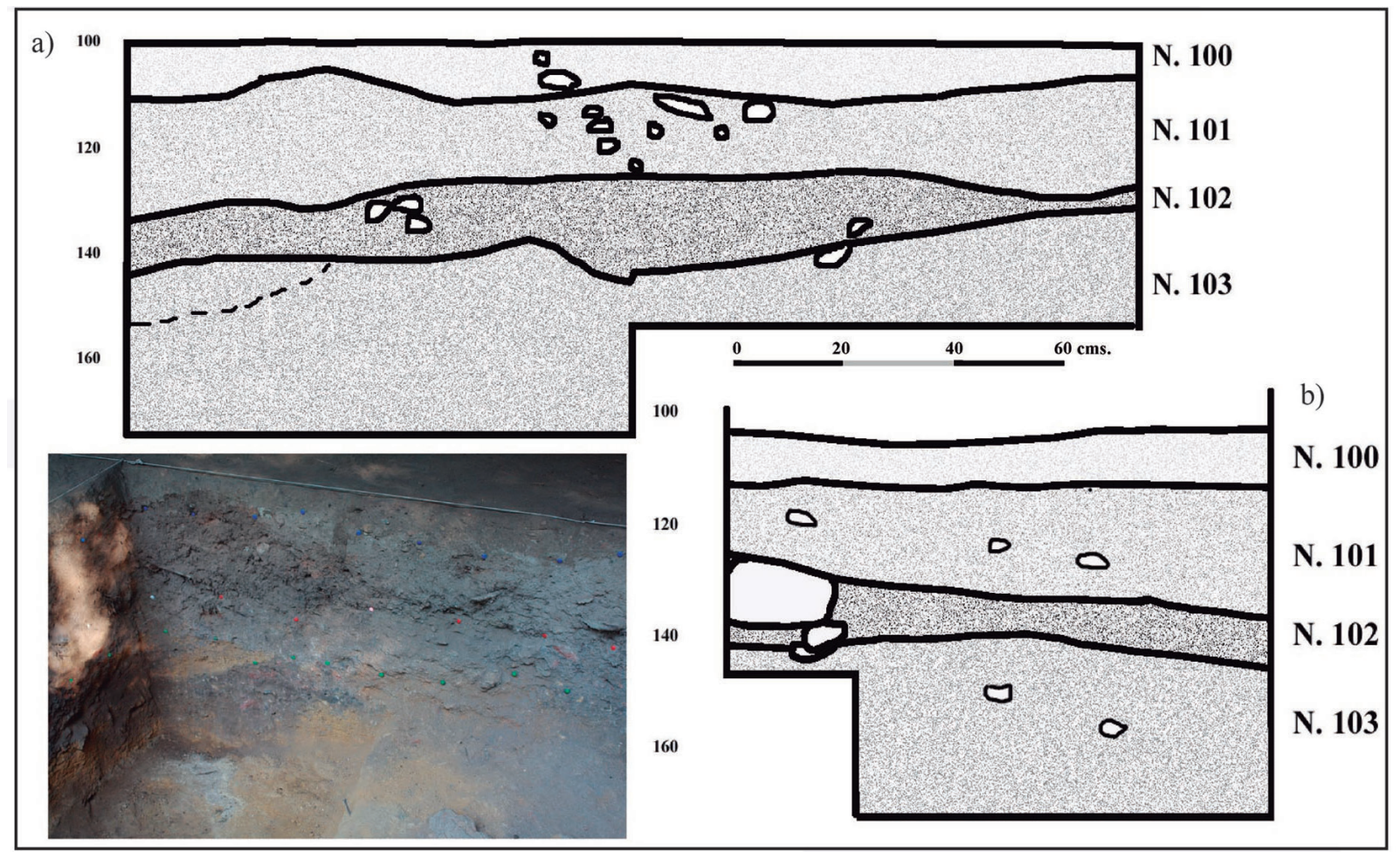

Fig. 3. Secuencia estratigráfica del abrigo de Martinarri (Obécuri, Condado de Treviño): a) perfil meridional de los cuadros Z1 y A1, b) perfil occidental del cuadro Z2. 
quiere una textura arenosa, suelta y de color marrón oscuro, todavía con numerosas raíces.

Los materiales arqueológicos no son muy abundantes. En general, se asemejan a los del nivel infrapuesto: unos pocos restos de fauna, residuos de talla, algún núcleo y sus avivados, diversos soportes laminares, un par de raspadores, láminas retocadas y una truncadura. Aparecen junto con los esperables, pero escasos, materiales modernos (loza vidriada, fragmentos de vidrio...).

Las unidades estratigráficas integradas en el nivel difieren en su naturaleza:

UE.2: estructura negativa que afecta mínimamente a los cuadros A2 (sector 4) y Z2 (sectores 5 y 6). De morfología subcircular profundiza 25 $\mathrm{cm}$, hasta el inicio del nivel 102. Se ha interpretado como una cata contemporánea (¿furtiva?) de la cual deben proceder los objetos prehistóricos que recogimos en nuestra primera visita. El relleno UE.3: es de similar caracteres que el nivel superficial, si bien sus responsables colocaron un bloque en el fondo para facilitar su cierre. Contenía material arqueológico de los niveles afectados.

UE.39: estructura negativa de morfología subcircular, identificada desde los inicios de la retirada del nivel superficial. Su desarrollo afecta al área sur del cuadro A4. Desconocemos su origen y funcionalidad, reconociendo su génesis moderna. El relleno UE.40: es muy similar al del nivel superficial, pero menos compacto. Sin apenas materiales prehistóricos, pero si modernos -vidrio y cerámica vidriada- .

Nivel 100: reconocido en los cuadros interiores con una potencia media de $15 \mathrm{~cm}$. Es de textura arenosa muy compacta, con raíces y casi sin piedras. En su formación participan fenómenos de meteorización de láminas arenosas desprendidas de la pared y del techo del abrigo: dominan los tonos rojizos, intercalándose manchas carbonosas. En el exterior la humedad, debida a encharcamientos ocasionados por goteo del reborde de la techumbre, modifica la coloración (tonos marrones oscuros).

En él se han identificado 15 agujeros de pequeño tamaño (14 en el cuadro Z1 y 1 en A1) (Tab. 1). Predominan las morfologías circularesovaladas (11), 2 con base cuadrangular.

Los diámetros oscilan entre $3-5 \mathrm{~cm}$ y las alturas son inferiores a 5 en 4 casos, entre 5 y 10 en 7 y por encima de 10 en 4 . Las características de los rellenos, lógicamente, difieren de las propias del nivel, incluyendo carbones en 7 casos. La serie de rasgos comunes, y su distribución restrin-

\begin{tabular}{|c|c|c|c|c|}
\hline UE & Sección & Dimensiones & $\begin{array}{c}\text { Desarrollo en } \\
\text { profundidad }\end{array}$ & Relleno \\
\hline $\mathbf{1 0 - 1 1}$ & Circular & $4 \times 6$ & 4 & Gris oscuro, arenoso y suelto \\
\hline $\mathbf{1 4 - 1 5}$ & Ovalada & $3 \times 4$ & 3 & Marrón oscuro, arenoso y suelto \\
\hline $\mathbf{1 6 - 1 7}$ & $\begin{array}{c}\text { Circular- } \\
\text { cuadrangular }\end{array}$ & $3 \times 3$ & 3,5 & Marrón oscuro y suelto \\
\hline $\mathbf{1 7 b i s - 1 8}$ & Circular & $4 \times 4$ & 7,5 & Gris, arenoso y suelto* \\
\hline $\mathbf{1 9 - 2 0}$ & Ovalada & $4 \times 3,5$ & 8 & Marrón oscuro, suelto* \\
\hline $\mathbf{2 1 - 2 2}$ & Circular & $5 \times 4$ & 5,5 & Marrón oscuro, suelto* \\
\hline $\mathbf{2 3 - 2 4}$ & Ovalada & $4 \times 4$ & 22 & Marrón oscuro, suelto \\
\hline $\mathbf{2 5 - 2 6}$ & Ovalada & $4 \times 4$ & 3 & Gris, suelto \\
\hline $\mathbf{2 7 - 2 8}$ & Circular & 3 & 2 & Marrón oscuro, suelto \\
\hline $\mathbf{2 9 - 3 0}$ & Circular & $2 \times 2,5$ & 10 & Marrón oscuro, arenoso y suelto \\
\hline $\mathbf{3 1 - 3 2}$ & Rectangular & $3 \times 4$ & 5 & Marrón oscuro, arenoso y suelto \\
\hline $\mathbf{3 3 - 3 4}$ & Ovalada & $3,5 \times 2$ & 8 & Marrón oscuro, arenoso y suelto* \\
\hline $\mathbf{3 5 - 3 6}$ & $\begin{array}{c}\text { Circular- } \\
\text { cuadrangular }\end{array}$ & $5 \times 5$ & 14 & Marrón oscuro, arenoso y suelto* \\
\hline $\mathbf{3 7 - 3 8}$ & Circular & $3,5 \times 2,5$ & 5,5 & Gris, arenoso y suelto* \\
\hline $\mathbf{4 1 - 4 2}$ & Cuadrangular & $5 \times 5$ & 15 & \\
\hline
\end{tabular}

Tab. 1. Listado y principales características de las unidades estratigráficas identificadas en el nivel 100 del abrigo de Martinarri (Obécuri, Condado de Treviño): en cada fila se caracteriza su perfil y sedimento (el asterisco indica restos de carbón). Las dimensiones están en $\mathrm{cm}$. 
gida permite su interpretación como resultado de una acción contemporánea: el clavado de estacas acuñadas para formalizar una estructura. Su ubicación en el interior del abrigo, donde la techumbre desciende, excluye que sea un cierre.

Consideramos el nivel 100 de formación prehistórica: lo denuncian los hallazgos materiales, mezclados con algunos pocos modernos rescatados en sus primeros centímetros. Como los agujeros de poste no cortan la interfacies y ocupan sus primeros centímetros se determinará su antigüedad datando una muestra de carbón, tras su identificación antracológica.

La UE.1 plantea dudas sobre su carácter prehistórico. Es una mancha carbonosa, con núcleo rojizo y apelmazado, entre ceniza blanquecina. Se detectó sobre mínimas partes de los cuadros A2 y A4, con un máximo de $7 \mathrm{~cm}$ del espesor y sin continuidad en el siguiente nivel. Es estéril. A falta de contraste con analíticas más específicas, la interpretamos como rastro de alguna tabla quemada en la actualidad. Recientemente hemos sabido que los pastores apoyaban maderas en el suelo y en el extremo del voladizo para mejorar la habitabilidad del abrigo.

En el nivel 100 los objetos líticos recuperados casi alcanzan el millar. Dominan los restos de talla, con profusión de láminas y unos pocos núcleos y sus avivados. Las piezas son dorsos (17, incluyendo algún triángulo), raspadores (10), muescas y denticulados junto con alguna raedera. Los restos de fauna se acercan al medio millar.

Nivel 101: alcanza $23 \mathrm{~cm}$ de potencia. En las áreas interiores es un sedimento arenoso de color marrón claro, más suelto que el que lo sella. Se va enriqueciendo con elementos de fracción mayor (clastos, bloques y elementos de cuarzo) cuando se profundiza. Al exterior es menos homogéneo, y su coloración varía del marrón oscuro y rojizo al marrón más claro: la variación es resultado de la mayor humedad del área y a la formación de pequeñas capas vegetales en los episodios de abandono.

En este horizonte, sin excavar por completo en los cuadros A1 y Z1, se ha identificado la UE.5: agujero de sección cuadrangular de $5 \times 5$ $\mathrm{cm}$ que profundiza $12 \mathrm{~cm}$, identificado en la segunda semitalla del nivel. Está relleno (UE.6) por un sedimento gris oscuro de textura arenosa y suelta, conteniendo 2 lasquitas de sílex. Posiblemente sea el resultado del clavado de una estaca.
En el nivel 101 el material prehistórico, es muy abundante (Fig. 4). La industria lítica consta de más de 3.600 elementos. De ellos 3.530 son restos de talla: avivados, golpes de buril (10), más de dos centenares de láminas y numerosos núcleos. Se han contado 158 piezas retocadas: casi la mitad son dorsos (más láminas -o sus fragmentos- que puntas), junto con pequeños triángulos y segmentos, añadiéndose raspadores (38), láminas retocadas (22), y escasas truncaduras, buriles, muescas y denticulados. Hay un percutor. Los fragmentos de fauna, pequeños, son 2.400 .

Nivel 102: con una potencia media de $20 \mathrm{~cm}$, se ha excavado al completo en los cuadros centrales y parcialmente en los exteriores. Del anterior se separa por una coloración algo más clara de los tonos marrones y por la compactación de las arenas que dificulta y ralentiza la excavación. En bastantes ocasiones una costra de arena recubre los objetos, cuya materia prima es irrecono-

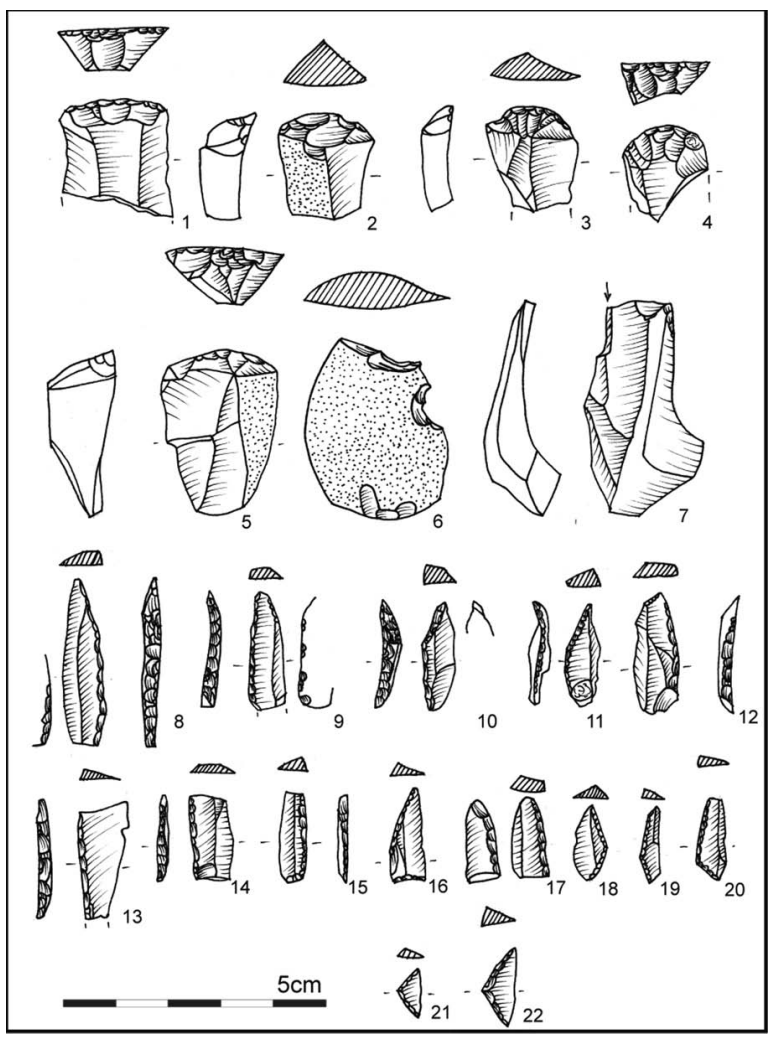

Fig. 4. Selección de piezas retocadas pertenecientes al nivel 101 de Martinarri (Obécuri, Condado de Treviño): 1 a 5-raspadores; 6- muesca; 7- buril; 8 a 17-dorsos; 18 a 22- triángulos. 
cible hasta la limpieza. En el exterior pierde esa compacidad, a la vez que su coloración adquiere tonos más amarillentos y el horizonte se enriquece con bastantes piedras y algunos bloques.

Entre los cuadros A2 y Z2 se aisló la UE.4, una mancha de tierra más oscura y disposición ovalada algo difuminada en sus límites y claramente asociada a bloques (diferentes en tamaño y redondez de los propios del nivel). Al interior se identifica un sedimento caracterizado por su compacidad y coloración marrón oscura/negruzca, con manchones grisáceos. Su espesor máximo es de $8 \mathrm{~cm}$. Una vez vaciado no se reconoció

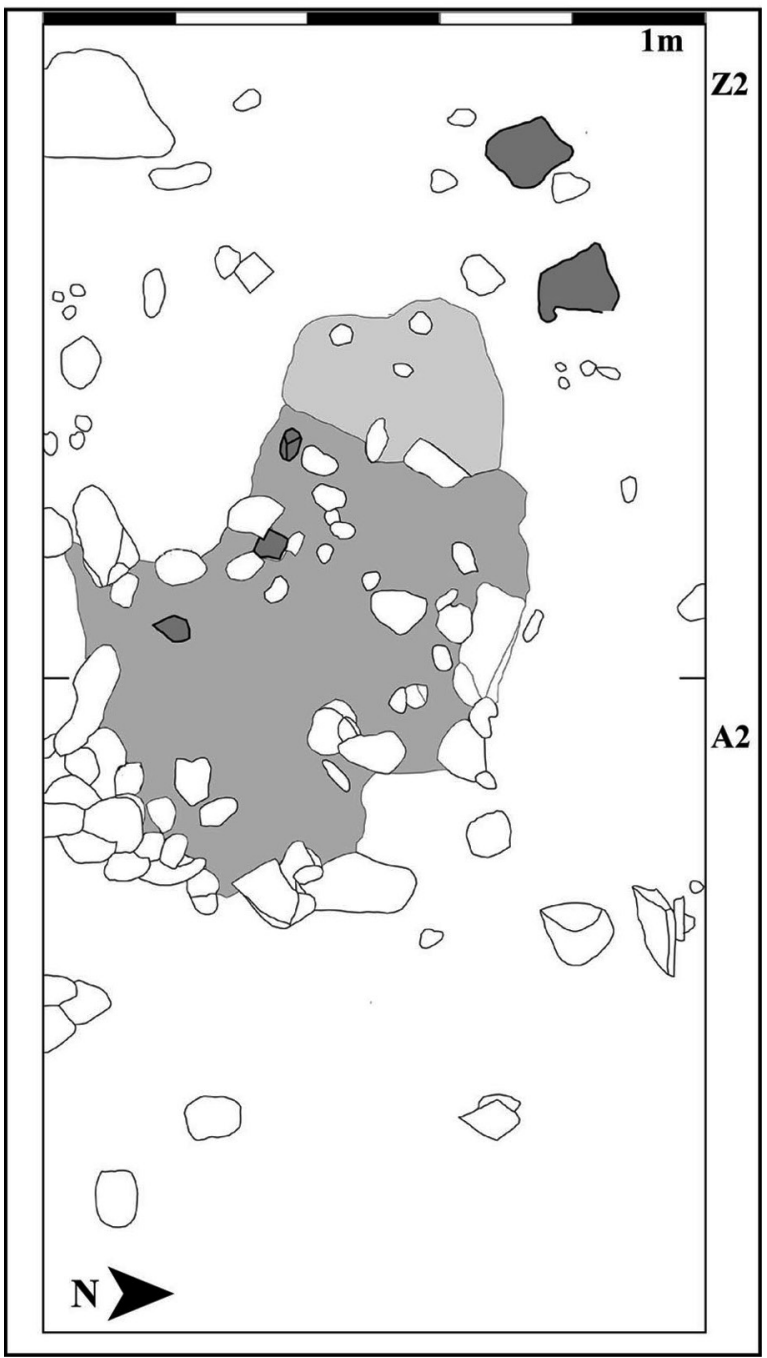

Fig. 5. Dibujo de la planta de la UE. 4 de Martinarri (Obécuri, Condado de Treviño), interpretada como una posible estructura de combustión. ninguna interfaz de corte (Fig. 5). Se ha interpretado como un hogar, ubicado en la parte central del abrigo, notando que en su material lítico son muy frecuentes las alteraciones térmicas. Reconocemos, no obstante, que algunos de sus caracteres son compartidos también por el nivel 102.

La industria lítica recuperada en la estructura comprende cinco centenares de objetos donde dominan los restos de talla, incluyendo núcleos (3) y avivados (4). Lo retocado se reduce a 2 raspadores, 1 truncadura y 1 denticulado. Nos parece llamativa la diferencia en la composición de la industria de la unidad frente a la propia del nivel 102: ¿por la diferente función de cada área? La fauna incluye dos centenares y medio de pequeños fragmentos. Incluye placas de areniscas cuya naturaleza, en este y en los demás casos, antrópica o natural aún no está clara.

El nivel 102 tiene una llamativa riqueza arqueológica: 3.700 objetos líticos en la pequeña área excavada (Fig. 6). Algo más de 3.500 son

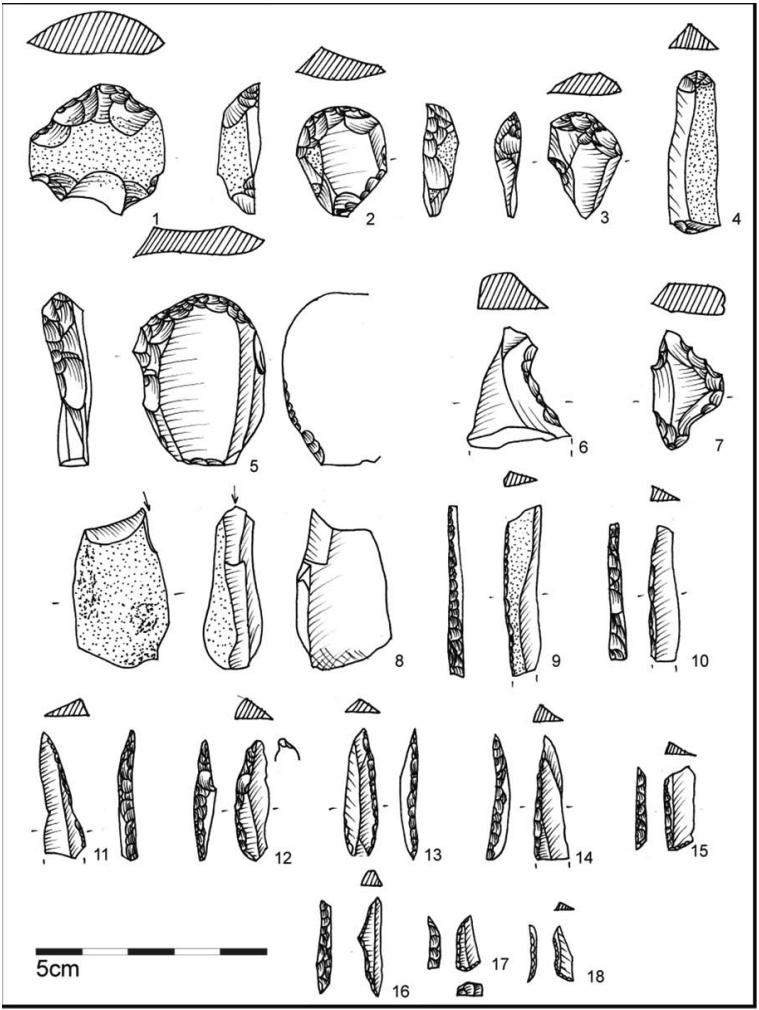

Fig. 6. Selección de piezas retocadas pertenecientes al nivel 102 de Martinarri (Obécuri, Condado de Treviño): 1 a 5- raspadores; 6 y 7 - denticulados; 8 - buril; 9 a 18 dorsos. 
restos de talla: abundantes avivados, flancos de núcleos y láminas cresta, así como núcleos, golpes de buril y 150 láminas sin retocar. Los objetos retocados, 170, están dominados por los dorsos, sin que falten los raspadores (45), ni las láminas retocadas (37), más algunos perforadores, buriles, raederas, muescas y truncaduras. También en este nivel dominan los dorsos (más láminas que puntas). De nuevo hay triángulos ultramicrolíticos. Entre los 3.370 fragmentos de fauna se reconocen dientes y restos de microfauna. Destacamos un colgante sobre canino atrófico de ciervo, un punzón de hueso, varios ocres y placas de arenisca. Nivel 103: es la última unidad litoestratigráfica con interés arqueológico. Sus 15 centímetros de potencia están rellenos de una matriz granulosa con gravas y areniscas, es de tonos amarillentos, grisáceos y rojizos según zonas y de menor compacidad que el superior.

$\mathrm{Su}$ registro material es bastante notable, pues suma 1.300 elementos líticos en dos metros cuadrados: en su mayoría son restos de talla con 42 láminas, 7 núcleos y bastantes avivados. Los objetos retocados son dorsos (15, más láminas que puntas) y raspadores (4) que se complementan con truncaduras, raederas, denticulados y un buril (Fig. 7). La fauna incluye 900 fragmentos, con unos pocos dientes y significativos restos de microfauna. Aparecen de nuevo placas de areniscas y carbones.

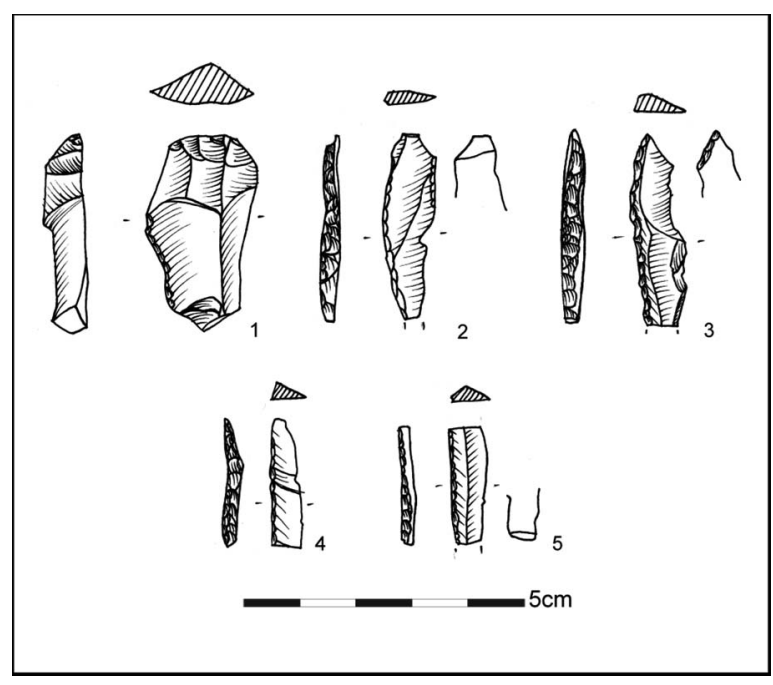

Fig. 7. Selección de piezas retocadas pertenecientes al nivel 103 de Martinarri (Obécuri, Condado de Treviño): 1- raspador; 2 a 5-dorsos.
La suma de las piezas arqueológicas rescatadas en Martinarri superan las 16.600 evidencias: la fauna representa el $38 \%$ del total, los sílex el $62 \%$, contando también con percutores e industria ósea.

\section{PARALELOS CRONOLÓGICOS Y EVALUACIÓN INDUSTRIAL}

Para comprender la dinámica de ocupación del territorio durante las fases de vigencia de Martinarri, exponemos en la tabla 2 las fechas C14 que son contemporáneas a las del abrigo, así como las de períodos colindantes (niveles F2, G, $\mathrm{H} 2$ de Atxoste) o intermedios entre sus niveles (Portugain y nivel II de Urratxa III).

La ocupación de Martinarri cuenta con dos dataciones radiocarbónicas, inéditas hasta ahora, sobre muestras óseas singulares, de imposible identificación a nivel de especie: $8455 \pm 45$ BP, recogida en el nivel 102 , cuadro $\mathrm{Z} 2$, a $128 \mathrm{~cm}$ bajo el plano 0 y $11890 \pm 50 \mathrm{BP}$ en el nivel 103, cuadro A2, a $146 \mathrm{~cm}$ bajo el plano 0 .

La más antigua sitúa el inicio de la ocupación del abrigo en los últimos momentos del Pleistoceno, en el intervalo temporal donde se ha establecido el tránsito entre el Magdaleniense final y el Aziliense en la cornisa cantábrica. A partir del registro y dataciones de los yacimientos de Anton Koba, Berroberría, Cualventi, Cueto de la Mina, Cueva Oscura de Ania, La Garma A, Laminak II, Langatxo, El Mirón y Zatoya, se ubica dicho tránsito en torno al 12000/11500 BP, planteando ahí el fin del Magdaleniense (Álvarez 2008: 75) y los inicios del Aziliense en el Alleröd (González Sainz 1994: 57; Fernández-Tresguerres 2006: 165).

La datación del nivel 103 es compatible con otras de la región: cinco de Atxoste: $11720 \pm 70$ $\mathrm{BP}, 11730 \pm 80 \mathrm{BP}, 11690 \pm 80 \mathrm{BP}, 11760 \pm 70 \mathrm{BP}$ y $11800 \pm 60$ BP (Barandiarán et al. 2006); dos de Anton Koba: $11800 \pm 330$ BP y $11700 \pm 180$ BP (Armendáriz 1997) y una de Kukuma $11550 \pm 130$ BP (Baldeón y Berganza 1996). Algo más alejadas geográficamente están las 3 del nivel II de Zatoya: $11840 \pm 240$ BP (Ly.1400), $11620 \pm 360$ BP (Ly.1599) y $11480 \pm 270$ BP (Ly.1399) (Barandiarán y Cava 1989) y la del nivel r2 de Abauntz: $11760 \pm 90$ BP (Utrilla et al. 2010). De la vertiente cantábrica proceden 3 más: la del nivel II de Laminak II, $11700 \pm 140$ BP (Ua-2362) (Berganza 
y Arribas 1994), la del nivel I de Langatxo, $11900 \pm 125$ BP (Ua-3327) (Soto Barreiro 2003: 430) y la del nivel II de Santa Catalina, $11460 \pm 420$ BP (Arribas 2005).

A estas referencias arqueológicas se sumarían otras del territorio más próximo que, o bien carecen de dataciones absolutas, o en el caso de poseerlas no resultan fiables por diferentes motivos. El primer grupo reúne los yacimientos de Atabo, Coscobilo, Arrillor y Peña del Castillo. El segundo incluye el nivel II de El Montico de Charratu cuya datación, $14470 \pm 200 \mathrm{BP}$, a partir de conchas de Helix, pudiera no tener correspondencia con el contenido material (Barandiarán et al. 2006).

Se ha señalado la dificultad de encajar estos conjuntos de finales del Tardiglaciar en el Magdaleniense final o Aziliense (Cava 2004b; Berganza 2005; Barandiarán et al. 2006). A pesar de la definición detallada de las principales transformaciones en los equipamientos líticos y óseos (González Sainz 1989-1995; Fernández-Tresguerres 2006), la complejidad y sutil gradación de los cambios, así como sus diferentes ritmos en según qué espacios, dificultan la parcelación de las dinámicas de transición. La escasa industria ósea, principal factor discriminante, y el conocimiento desigual de los conjuntos líticos (Cava 2004b, Berganza 2005; Barandiarán et al. 2006; Ormazábal 2008) añaden aún más dificultades (Barandiarán y Cava 2008: 289).

El nivel 103 de Martinarri muestra, en su composición lítica, escasa concordancia respecto a los conjuntos más típicos de finales del Paleolítico. En el abrigo, el tipo retocado principal es el dorso, escaseando los raspadores y los buriles, categorías industriales muy habituales en los yacimientos cantábricos clásicos. Su inventario óseo trabajado tampoco es acorde con el propio de esos sitios. Sin embargo, su aparente singularidad se repite en los horizontes basales del yacimiento de Atxoste. Además los no lejanos lugares de Anton Koba y Kukuma, así como los sitios de Portugain o Urratxa III, de cronología ligeramente más reciente, muestran que la versatilidad de las industrias es una de las características del momento: la diversidad es el verdadero patrón.

La fecha del nivel 102 de Martinarri coincide con el inicio del Mesolítico de muescas y denticulados en la Alta Cuenca del Ebro (Alday y Cava 2006: 291-294), cuyo desarrollo se sitúa entre el IX y la primera mitad del VIII milenio
(Alday 2006: 314). Varias capas de yacimientos geográficamente próximos ofrecen valores similares para contextos industriales de muescas y denticulados: el D $8840 \pm 50$ BP y el VI $8760 \pm 80$ $\mathrm{BP}, 8510 \pm 80 \mathrm{BP}$ de Atxoste y el $8200 \pm 70 \mathrm{BP}$, $7920 \pm 100$ BP de Kanpanoste (Cava 2004a). En la zona pirenaica los horizontes $\mathrm{C}$, B de Berroberria han sido considerados sauveterroides y de denticulados respectivamente (Alday y Cava 2006): C $8860 \pm 100 \mathrm{BP}(\mathrm{GrN} .18425), 8630 \pm 70$ BP (GrN.18426), $8510 \pm 90$ BP (GrN.16618) y el B, $8800 \pm 80$ BP (GrN.18424), $8580 \pm 80$ BP (GrN.18422), $8470 \pm 80$ BP (GrN.16619) (Barandiarán 1993-1994). Asimismo es reseñable el nivel Ib de $8260 \pm 550 \mathrm{BP}$ (Ly.1457) y $8150 \pm 220$ BP (Ly.1398) (Barandiarán y Cava 1989), atendiendo a las observaciones de A. Cava (2004b) con respecto a la adscripción cultural -aziloidede su industria.

Las series industriales de esos conjuntos difieren notablemente de la del nivel 102 de Martinarri. Aquí los dorsos siguen siendo el utillaje mayoritario, $42 \%$ de los efectivos, seguidos por los raspadores y las raederas. Ello vincula el horizonte a un genérico Epipaleolítico/Mesolítico de tecnología microlaminar. Además hay que valorar la presencia de piezas significativas como son los pequeños triángulos que, en el nivel 101, se acompañan de elementos segmentiformes. Ambos tipos introducen unos más que interesantes matices sauveterrienses. Las referencias a industrias así denominadas en las proximidades de Martinarri nos retrotraen al $\mathrm{X}$ milenio. Corresponden a los niveles VIb, E y E2 de Atxoste, que presentan una industria predominantemente laminar con dorsos y elementos pigmeos, al yacimiento recientemente excavado de Socuevas, en Álava, con niveles inéditos del final del Paleolítico y del Mesolítico o, ya en la zona cantábrica, al nivel II de Ekain (Altuna y Merino 1984).

En el $\mathrm{X}$ milenio y en el mismo territorio, junto a estas industrias con evidencias sauveterrienses se reconocen otras dichas Azilienses (o en su tradición): nivel d de Abauntz $9530 \pm 300$ BP (Ly-1964) (Utrilla 1982-1983) y una de las ocupaciones de Berniollo $9940 \pm 490$ BP (Mariezkurrena 1990). La situación plantea la interesante cuestión de qué relación debe establecerse entre las facies industriales (Cava 2004b: 28).

Cerca de Martinarri, con una cronología semejante y adscripción a un Epipaleolítico microlaminar, se han mencionado los casos del nivel 
V de Mendandia, $8500 \pm 60$ BP (Alday 2005) y de Las Orcillas 1, $8610 \pm 50$ BP (Fernández Eraso et al. 2010). A pesar de lo escueto de sus industrias (el primero por su corta ocupación y el segundo por las intervenciones furtivas que han mermado su registro), definen una composición industrial concordante con la observada en Mar- tinarri, pero sin los tipos líticos de raigambre sauveterroide.

Los niveles superiores de Martinarri carecen de dataciones. Sin embargo, las consideraciones generales de sus inventarios líticos tallados se asimilan bien a las de la capa 102. Tomando con las reservas necesarias los datos, debido a que se

\begin{tabular}{|c|c|c|c|c|c|c|c|}
\hline Yacimiento & Nivel & Referencia & $\begin{array}{l}\text { Valor } \\
\text { mét }\end{array}$ & $\begin{array}{l}\text { dio- } \\
\text { co }\end{array}$ & $\begin{array}{c}\text { Calibración } \\
\text { CalPal } \\
2 \text { sigmas }\end{array}$ & $\begin{array}{l}\text { Caracte- } \\
\text { rización } \\
\text { tecnológica }\end{array}$ & Bibliografía \\
\hline Anton Koba & VIII & I-16236 & 11800 & 330 & $14880-12920$ & $\mathrm{AZ}$ & Armendáriz 1997 \\
\hline Anton Koba & VIII & I-17479 & 11700 & 180 & $13970-13210$ & $\mathrm{AZ}$ & Armendáriz 1997 \\
\hline Atxoste & $\begin{array}{c}\text { VI } \\
\text { VI } \\
\text { D } \\
\text { E } \\
\text { VIb2 } \\
\text { E2 } \\
\text { VI } \\
\text { E } \\
\text { E2 } \\
\text { VIIc } \\
\text { VIIb } \\
\text { H } \\
\text { VIIc } \\
\text { VIIc } \\
\text { F } \\
\text { F } \\
\text { F2 } \\
\text { G } \\
\text { H2 }\end{array}$ & $\begin{array}{l}\text { GrA-15700 } \\
\text { GrA-15699 } \\
\text { GrA-13473 } \\
\text { GrA-35141 } \\
\text { GrA-35142 } \\
\text { GrN-26664 } \\
\text { GrA-15858 } \\
\text { GrN-26663 } \\
\text { GrN-26665 } \\
\text { GrA-23107 } \\
\text { GrA-22865 } \\
\text { GrA-19870 } \\
\text { GrA-22866 } \\
\text { GrA-22900 } \\
\text { GrN-26666 } \\
\text { GrN-26667 } \\
\text { GrA-19554 } \\
\text { GrA-19502 } \\
\text { GrA-19503 }\end{array}$ & $\begin{array}{l}8510 \\
8760 \\
8840 \\
9450 \\
9510 \\
9510 \\
9550 \\
9650 \\
9820 \\
11690 \\
11720 \\
11730 \\
11760 \\
11800 \\
11910 \\
11960 \\
12070 \\
12200 \\
12540\end{array}$ & $\begin{array}{c}80 \\
50 \\
50 \\
50 \\
50 \\
150 \\
60 \\
150 \\
150 \\
80 \\
70 \\
80 \\
70 \\
60 \\
170 \\
180 \\
60 \\
90 \\
80\end{array}$ & $\begin{array}{c}9600-9400 \\
9990-9550 \\
10250-9650 \\
10860-10540 \\
11170-10570 \\
11300-10380 \\
11190-10630 \\
11390-10550 \\
11870-10670 \\
13800-13360 \\
13810-13450 \\
13810-13450 \\
13810-13530 \\
13830-13550 \\
14420-13380 \\
14630-13390 \\
14340-13700 \\
14780-13820 \\
15280-14680\end{array}$ & $\begin{array}{l}\text { MD } \\
\text { MD } \\
\text { MD } \\
\text { ML } \\
\text { ML } \\
\text { ML } \\
\text { ML } \\
\text { ML } \\
\text { ML } \\
\text { MG } \\
\text { MG } \\
\text { MG } \\
\text { MG } \\
\text { MG } \\
\text { MG } \\
\text { MG } \\
\text { MG } \\
\text { MG } \\
\text { MG }\end{array}$ & $\begin{array}{c}\text { Alday y Cava } 2006 \\
\text { Alday y Cava } 2006 \\
\text { Alday y Cava } 2006 \\
\text { Alday } 2002 \\
\text { Alday } 2002 \\
\text { Alday } 2002 \\
\text { Inédita } \\
\text { Inédita } \\
\text { Inédita } \\
\text { Barandiarán et al. } 2006 \\
\text { Barandiarán et al. } 2006 \\
\text { Barandiarán et al. } 2006 \\
\text { Barandiarán et al. } 2006 \\
\text { Barandiarán et al. } 2006 \\
\text { Barandiarán et al. } 2006 \\
\text { Barandiarán et al. } 2006 \\
\text { Barandiarán et al. } 2006 \\
\text { Barandiarán et al. } 2006 \\
\text { Barandiarán et al. } 2006\end{array}$ \\
\hline Berniollo & II & I-14786 & 9940 & 490 & $13000-10040$ & ML & Baldeón y Berganza 1996 \\
\hline Kukuma & Lecho 11 & Ua-2625 & 11550 & 130 & $13700-13180$ & MG & Baldeón y Berganza 1996 \\
\hline Martinarri & $\begin{array}{l}102 \\
103\end{array}$ & $\begin{array}{l}\text { GrA-46014 } \\
\text { GrA-45940 }\end{array}$ & $\begin{array}{c}8455 \\
11890\end{array}$ & $\begin{array}{l}45 \\
50\end{array}$ & $\begin{array}{c}9560-9400 \\
13960-13560\end{array}$ & $\begin{array}{l}\text { ML } \\
\text { MG }\end{array}$ & $\begin{array}{l}\text { Inédita } \\
\text { Inédita }\end{array}$ \\
\hline Mendandia & V & GrA-6874 & 8500 & 60 & $9580-9420$ & ML & Alday 2005 \\
\hline M Charratu & II & I-10767 & 14470 & 200 & $18010-17130$ & MG? & Baldeón et al. 1983 \\
\hline Las Orcillas 1 & & Beta-252434 & 8610 & 50 & $9690-9490$ & ML & Fernández Eraso et al. 2010 \\
\hline Portugain & I & GrN-14097 & 10370 & 90 & $12690-11890$ & $\mathrm{AZ}$ & Barandiarán y Cava 2008 \\
\hline Urratxa & II & Ua-11433 & 10240 & 100 & $12690-11890$ & $\mathrm{AZ}$ & Muñoz y Berganza 1997 \\
\hline
\end{tabular}

Tab. 2. Relación de yacimientos contemporáneos a Martinarri con dataciones con desviaciones menores a 100 años (Atxoste VI, VIb2, VIIb, VIIc, D, E, H, F2, G, H2; Mendandia; Las Orcillas 1; Portugain; Urratxa) y superiores a 100 años (sombreadas Atxoste E2, E, F; Antón Koba; Berniollo; Kukuma; Montico de Charratu): MG Magdaleniense, AZ Aziliense, ML Mesolítico laminar, MD Mesolítico de muescas y denticulados. La calibración de las fechas se ha realizado empleando el programa CalPal (Weninger et al. 2007). 


\begin{tabular}{|l|c|c|c|c|}
\hline \multicolumn{1}{|c|}{ Niveles } & $\mathbf{1 0 0}$ & $\mathbf{1 0 1}$ & $\mathbf{1 0 2}$ & $\mathbf{1 0 3}$ \\
\hline Raspadores & 25,6 & 24 & 25,5 & 8,3 \\
\hline Raederas & 10,2 & 13,9 & 23,8 & 12,5 \\
\hline $\begin{array}{l}\text { Muescas y } \\
\text { denticulados }\end{array}$ & 17,9 & 2,5 & 1,7 & 4,1 \\
\hline Perforadores & 0 & 1,2 & 1,7 & 0 \\
\hline Buriles & 0 & 2,5 & 1,7 & 4,1 \\
\hline Écaillés & 0 & 1,2 & 0 & 0 \\
\hline Truncaduras & 0 & 1,8 & 0,5 & 8,3 \\
\hline Dorsos & 41 & 49,3 & 42,6 & 62,5 \\
\hline Triángulos & 5,1 & 3,1 & 2,2 & 0 \\
\hline
\end{tabular}

denticulados. El perfil del nivel 103 es muy diferente (Fig. 10).

Otras consideraciones particulares son significativas y complementan lo señalado. Los buriles nunca son muy numerosos, pero su $4 \%$ en el nivel 103, sumado al porcentaje de las truncaduras, marca una clara diferencia respecto a las demás capas. Es llamativa la alta participación de los dorsos en el nivel 103 y menor, pero igualmente importante, en los conjuntos superiores. Aunque un análisis detallado es aún prematuro podemos

Tab. 3. Distribución de frecuencias relativas de las piezas retocadas por niveles del abrigo de Martinarri (Obécuri, Condado de Treviño).

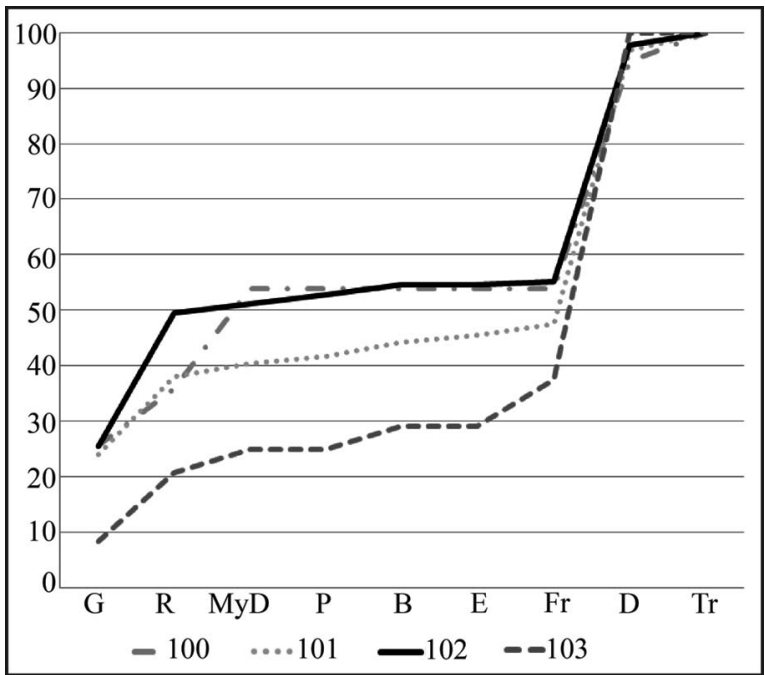

Fig. 8. Representación gráfica de la distribución de frecuencias relativas de las piezas retocadas por niveles de Martinarri (Obécuri, Condado de Treviño).

trata de una básica aproximación, las colecciones pivotan sobre dos familias, dorsos y raspadores, cuya suma supera, en cada caso, los dos tercios de los efectivos (Tab. 3).

Por tanto asistimos a una especialización en dichos componentes donde las raederas -entre las que hemos incluido bastantes láminas con retoques minimales- tienen una contribución que disminuye a techo. La figura 8 (Fig. 8), que acumula los porcentajes de cada categoría por estratos, muestra la similaridad de los perfiles de los tres superiores, salvo por el descenso continuo de raederas y, en paralelo, el ascenso de muescas y

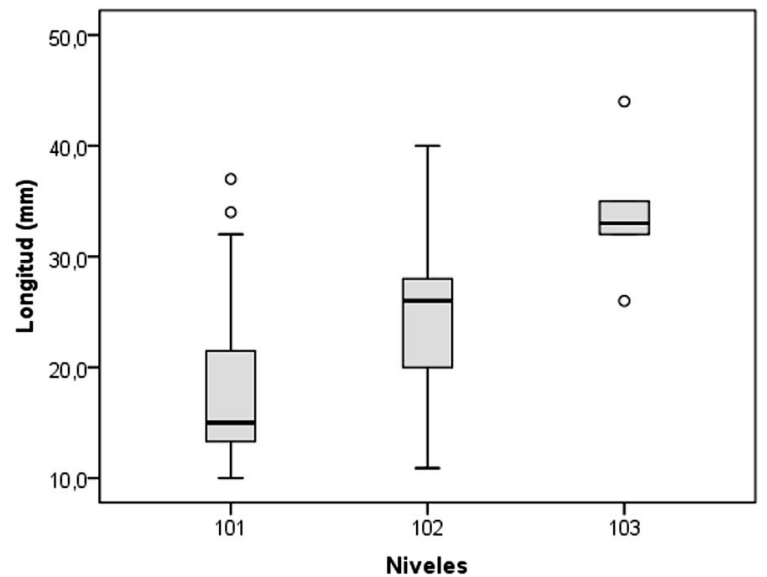

Fig. 9. Evolución dimensional de las puntas de dorso por niveles de Martinarri (Obécuri, Condado de Treviño).

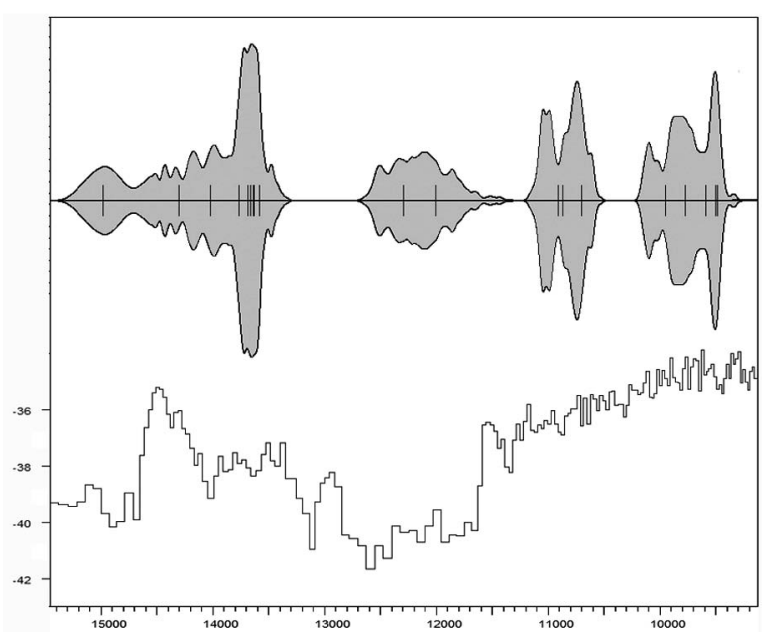

Fig. 10. Representación gráfica de las dataciones disponibles para el Alto Valle del Ebro en el Tardiglaciar (Tab. 2). Calibración Cal Pal (Weninger et al. 2007) a dos sigmas. Curva climática GISP 160/180: nótese el enfriamiento del Younger Dryas. Escala cronológica en años cal BP. 
anotar algunas diferencias en esta categoría industrial: a) evolución morfodimensional de las series por capas; b) presencia de dorsos dobles o con base redondeada en 101 y 102; c) ejemplares con finos retoques simples opuestos al dorso; d) pequeños dorsos arqueados (segmentiformes) en $101 \mathrm{y}$; d) pequeños triángulos en 101 y 102.

Para calibrar mejor la evolución de los dorsos se han analizado sus variaciones de tamaño a lo largo de la secuencia estratigráfica. Se ha considerado la longitud de las piezas completas o de las que, estando fragmentadas, pueden reconstruirse por aproximación (Fig. 9). Se observa como el tamaño medio se reduce según avanzamos en el tiempo. Es un proceso de microlitización que nos remite a las dinámicas descritas para las industrias del Tardiglaciar y de los primeros momentos holocénicos, concordando así con lo indicado a partir de las dataciones.

El abrigo de Atxoste es una referencia necesaria para Martinarri, por su proximidad geográfica, cronológica e industrial. En sus niveles inferiores, que se corresponden con el final del Paleolítico y los inicios del Mesolítico, los dorsos son, también, los objetos más numerosos. En su evolución la longitud y el índice de alargamiento disminuyen cuanto más reciente es el estrato, hecho que, de nuevo, coincide con la presencia de pequeños triángulos y elementos segmentiformes (Barandiarán et al. 2006).

Para discutir el proceso de ocupación de esta región de la Cuenca Alta del Ebro hemos elaborado la figura 10 a partir de las fechas pertinentes comentadas en el texto (Tab. 2 y Fig. 10). La serie de C14 calibrada muestra cuatro agrupaciones discontinuas, que representan los primeros conatos de ocupación de este territorio interior, previos a la estabilización holocénica.

El agrupamiento más antiguo abarca entre circa 15000 al 13400, y corresponde a los niveles inferiores de Atxoste y al 103 de Martinarri (así como, en su límite más reciente, a los de Socuevas). Las condiciones climáticas nos sitúan en un interestadial compatible con el episodio GI 1e a $1 \mathrm{c}$ en la nueva propuesta cronoclimática GICC05 (Lowe et al. 2008).

El segundo nos sitúa entre el 12800 y el 11700, representado en Portugain y Urratxa III. La curva climática corresponde al Younger Dryas (o episodio SG1 de GICC05). Las condiciones frías están bien reflejadas en los sedimentos de Portugain, y nos resulta desconcertante que, en esos momen- tos de rigurosidad, los dos campamentos conocidos se ubiquen en parajes muy montañosos a casi, o rebasando, los 1.000 m.s.n.m. El caso de Portugain se puede atribuir a la atracción que ejerce el abastecimiento de los sílex de Urbasa (Alday Cava y Tarriño 2007-2008).

El tercero ocupa el período comprendido entre el 11200 y el 10600. Las fechas pertenecen al yacimiento de Atxoste (coincidente con el desarrollo del horizonte III de Socuevas), situándonos a las puertas del Holoceno.

El agrupamiento más reciente, del 10200 al 9400, reúne a un importante número de yacimientos agrupados geográficamente: Martinarri 102, Mendandia V, Atxoste VI y D y Las Orcillas 1. La mejoría climática sigue su progreso, consolidándose en el Boreal el poblamiento de la región.

\section{RECAPITULACIÓN FINAL}

En los paisajes abiertos de la Llanada alavesa, en los valles que la encajan por el oeste y el sur e, incluso, en sus contrafuertes montañosos, se van reconociendo las huellas de los grupos que habitaron la Alta Cuenca del Ebro a finales del Pleistoceno y en las primeras fases del Holoceno. El abrigo de Martinarri con su valioso registro arqueológico, junto a una decena de asentamientos más, es un punto de la red que permite la explotación de una biomasa en crecimiento y el aprovechamiento de los muy ricos afloramientos silíceos de la región. En concreto el abrigo de Martinarri fue residencia de poblaciones asentadas en dos momentos, final del Pleistoceno e inicios del Holoceno, con un hiatus intermedio.

Por su ubicación, en una cubeta donde se entrecruzan barrancos, Martinarri se escapa del modelo habitual de los emplazamientos mesoneolíticos, los cuales, salvo excepciones, son ocupados poco después de abandonarse el que tratamos. Dicho patrón, buscando emplazamientos donde convergen biotopos de valle y de montaña, está consolidado en Atxoste y Socuevas pero no en Martinarri, Portugain o Kukuma.

Las evidencias recuperadas (industriales, faunísticas, de estructuras...) permitirán una serie de observaciones sobre la vida en Martinarri, pero su correcta valoración en cuanto a ritmos de ocupación, actividades desarrolladas, territorios de capta- 
ción... requerirá la finalización de su excavación y el consiguiente estudio del registro. No obstante, la evaluación general de la composición industrial y la información radiocronológica permiten definir, ya, dos problemáticas relevantes en el poblamiento de la Alta Cuenca del Ebro durante el Tardiglaciar y sus tiempos posteriores. La primera concierne a la comparación tanto de los patrones de explotación del medio, como de los conjuntos industriales del territorio respecto a las clásicas secuencias de la cornisa cantábrica. La segunda a la compleja evolución de las industrias postpaleolíticas.

La más antigua ocupación de Martinarri es contemporánea a Socuevas, Kukuma, Atxoste (algo anterior) y Anton Koba. Cronológicamente ocupan el lugar destinado a las fases finales del Magdaleniense cantábrico, si bien Anton Koba se ha atribuido al Aziliense por la presencia de un arpón óseo característico del período. Las industrias líticas de estos conjuntos ubicados en la vertiente mediterránea son, aparentemente, más homogéneas o, si se quiere, menos polimorfas, que las litorales cantábricas. El dominio de los dorsos y la importante contribución de los raspadores (frente al escaso papel de los buriles) merecen un análisis futuro. Otra nota discordante es la parquedad de objetos óseos en los campamentos de la vertiente meridional.

La complejidad de los procesos industriales tras su deslinde de la tradición paleolítica, queda clara en la segunda fase de ocupación de Martinarri que, según el carácter del inventario y la cronología, se ajusta a la primera de las unidades mesolíticas: microlaminar. Este es un apodo versátil, genérico, para encajar diversas situaciones aún por definir con detalle: una pequeña colección en Mendandia, un conjunto descontextualizado en Las Orcillas 1 y unas colecciones por analizar en Atxoste, Socuevas y Martinarri. La presencia en los tres últimos de pequeños triángulos y de dorsos curvados (segmentiformes) propone unos matices sauveterroides que es preciso valorar con cuidado en su contexto cronológico, en su relación con tradiciones aziloides y en su parentesco con producciones del Norte de los Pirineos. Hay que precisar el sentido de la evolución interna de esos artefactos a lo largo de un milenio, según el C14, que nos deja a las puertas del Mesolítico de muescas y denticulados. Con los encabalgamientos que imponen las desviaciones radiocronológicas, el final de estas industrias parece coincidir con el inicio de la de muescas y denticulados.
Estamos en las primeras fases de trabajo en el abrigo de Martinarri, pero los datos obtenidos ya lo señalan como un depósito arqueológico de gran interés, tanto por la riqueza de su contenido como por los momentos cronológicos y culturales implicados. Deberá completarse su excavación, ampliando las superficies de actuación y, si las condiciones lo permiten, mejorando el ritmo de trabajo, siendo prioritaria la datación de los niveles superiores, y por supuesto, el estudio detallado de sus colecciones industriales, faunísticas, palinológicas y antracológicas.

\section{AGRADECIMIENTOS}

El desarrollo de este trabajo no hubiera sido posible sin la colaboración de compañeros y estudiantes: nuestro más sincero agradecimiento a todos. El yacimiento se ha beneficiado de su integración en la línea de investigación del Grupo de Investigación de Alto Rendimiento de Prehistoria de la Universidad del País Vasco, HAR200803976/HIS. Asimismo su estudio es objeto del proyecto Las comunidades humanas de la alta cuenca del Ebro en la Transición PleistocenoHoloceno del Ministerio de Ciencia e Innovación HAR2011-26364.

\section{BIBLIOGRAFÍA}

Alday, A. 1998: El depósito prehistórico de Kanpanoste Goikoa (Vírgala, Álava). Memoria de las actuaciones arqueológicas, 1992-1993. Memorias de yacimientos alaveses 5, Diputación Foral de Álava. Vitoria-Gasteiz.

Alday, A. 2002: "Las unidades industriales mesolíticas en la alta-Media Cuenca del Ebro". Complutum 13: 19-50.

Alday, A. 2005: "La dinámica cultural del Mesolítico laminar: Mendandia y la cuenca valle del Ebro". En A. Alday (ed.): El campamento prehistórico de Mendandia: ocupaciones mesolíticas y neoliticas entre el 8500 y el 6400 B.P. Colección Barandiarán 9, Fundación J. M. de Barandiarán y Diputación Foral de Álava. Vitoria-Gasteiz: 607-611.

Alday, A. 2006: "El mesolítico de muescas y denticulados en la cuenca del Ebro y el litoral mediterráneo peninsular: síntesis de los datos". En A. Alday (ed.): El mesolítico de muescas y denticulados en la cuenca del Ebro y el litoral mediterráneo peninsular. Memorias de yacimientos alaveses 11, Diputación Foral de Álava. Vitoria-Gasteiz: 303-317. 
Alday, A. y Cava, A. 2006: "La unidad de muescas y denticulados del Mesolítico en el País Vasco: la formalización de un modelo cultural". En A. Alday (ed.): El mesolítico de muescas y denticulados en la cuenca del Ebro y el litoral mediterráneo peninsular. Memorias de yacimientos alaveses 11, Diputación Foral de Álava. Vitoria-Gasteiz: 223-300.

Alday, A.; Cava, A. y Tarriño, A. 2007-2008: "La circulación de materias primas líticas en la transición Mesolítico/Neolítico antiguo en el País Vasco. Los abrigos de Mendandia, Kanpanoste y Aizpea”. Veleia 24-25: 581-610.

Altuna, J. y Merino, J. M. 1984: El yacimiento prehistórico de la cueva de Ekain (Deba, Guipúzcoa). Colección Barandiarán 1, Eusko Ikaskuntza. San Sebastián.

Álvarez, D. 2008: "La cronología del tránsito Magdaleniense/Aziliense en la región cantábrica”. Complutum 19 (1): 67-78.

Armendáriz, A. 1997: "Anton Koba: cazadores azilienses en la sierra de Aizkorri (Gipuzkoa)". En P. Bueno Ramírez y R. de Balbín (coord.): II Congreso de Arqueología Peninsular (Zamora 1996) I: 297-310. Zamora.

Arribas, J. L. 2005: "El Magdaleniense Superior-final: espacio y tiempo en el territorio vasco". Munibe (Antropologia-Arkeologia) 57, Homenaje a Jesús Altuna: 239-247.

Baldeón, A. y Berganza, E. 1996: El yacimiento epipaleolítico de Kukuma: un asentamiento de cazadores-recolectores en la llanada alavesa (Araia, Álava). Memorias de yacimientos alaveses 3, Diputación Foral de Álava. Vitoria-Gasteiz.

Baldeón, A.; Berganza, E. y García, E. 1983: “Estudio del yacimiento de 'El Montico de Charratu' (Albaina, Treviño)". Estudios de Arqueología Alavesa 11: 121-186.

Barandiarán, I. 1993-1994: “Cueva de Berroberría (Urdax): informe de las campañas de excavación V (1990), VI (1991), VII (1992) y VIII (1993)”. Trabajos de Arqueología Navarra 11: 243-247.

Barandiarán, I. y Cava, A. 1989: “El yacimiento prehistórico de Zatoya (Navarra). Evolución ambiental y cultural a finales del Tardiglaciar y en la primera mitad del Holoceno". Trabajos de Arqueología $\mathrm{Na}$ varra 8: 291-352.

Barandiarán, I. y Cava, A. 2008: “Interpretación del sitio de Portugain en Urbasa". En I. Barandiarán y A. Cava: Cazadores y tallistas en el abrigo de Portugain: una ocupación de Urbasa durante el Tardiglaciar. Colección Barandiarán 12, Fundación J. M. de Barandiarán. Ataún: 267-314.

Barandiarán, I.; Cava, A. y Alday, A. 2006: “Ocupaciones de altura e interior durante el Tardiglaciar: la Llanada alavesa y sus estribaciones montañosas". En J. M. Maíllo y E. Baquedano (eds.): Miscelánea en homenaje a Victoria Cabrera. Zona Arqueológica 7, (1): 534-551.

Berganza, E. 2005: "El tránsito del Tardiglacial al Holoceno en el País Vasco". Munibe (Antropologia-Arkeologia) 57, Homenaje a Jesús Altuna: 249-258.

Berganza, E. y Arribas, J. L. 1994: “El asentamiento paleolítico de Laminak II (Berriatua, Bizkaia)". Kobie. Paleoantropología 21: 5-253.

Cava, A. 2004a: La ocupación prehistórica de Kanpanoste en el contexto de los cazadores-recolectores del Mesolítico. Memorias de yacimientos alaveses 9, Diputación Foral de Álava. Vitoria-Gasteiz.

Cava, A. 2004b: "Los procesos culturales del comienzo del Holoceno en la cuenca del Ebro y su contextualización". Salduie 4: 17-40.

Cava, A.; Barandiarán, I. y Alday, A. 2009: "The Mesolithic in the Ebro Basin (Spain)". En J. M. Burdukiewicz, K. Cyrek, P. Dyczek y K. Szymczak (eds): Understanding the past. Papers offered to Stefan K. Kozlowski. Universidad de Varsovia. Varsovia: 75-90.

Fernández Eraso, J.; García Rojas, M.; Fernández Crespo, T.; Castaños, P.; Bailon, S.; Murelaga, X. y Tarriño, A. 2010: "La cueva de Las Orcillas 1: una estación de los últimos cazadores-recolectores en La Berrueza (Mendaza-Acedo, Navarra)". Trabajos de Arqueología Navarra 22: 13-91.

Fernández-Tresguerres, J. A. 1995: "El Aziliense de la región cantábrica". En A. Moure y C. González Sainz: El final del Paleolítico cantábrico. Universidad de Cantabria. Santander: 199- 224.

Fernández-Tresguerres, J. A. 2006: "El Aziliense de la región cantábrica”. Zephyrus 59: 163-179.

González Sainz, C. 1989: El Magdaleniense SuperiorFinal de la región cantábrica. Ediciones Tantín. Universidad de Cantabria.

González Sainz, C. 1994: "Sobre la cronoestratigrafía del Magdaleniense y Aziliense en la región cantábrica". Munibe (Antropologia-Arkeologia) 48: 5368.

González Sainz, C. 1995: “13000-11000 BP. El final de la época magdaleniense en la región cantábrica”. En A. Moure y C. González Sainz: El final del Paleolítico cantábrico. Universidad de Cantabria. Santander: 159-197.

Lowe, J. J.; Rasmussen, S. O.; Björck, S.; Hoek, W. Z.; Steffensen, J. P.; Walker, M. J. C. y Yu, Z. C. 2008: "Synchronisation of palaeoenvironmental events in the North Atlantic region during the Last Termination: a revised protocol recommended by the INTIMATE group". Quaternary Science Reviews 27: 6-17.

Martín, R. y del Villar, J. 2005. Izki. Parque natural. Diputación Foral de Álava. Vitoria-Gasteiz: 1263.

Mariezkurrena, C. 1990: "Dataciones absolutas para la arqueología vasca". Munibe (Antropologia- Arkeologia) 42: 287-304. 
Muñoz, M. y Berganza, E. 1997: El yacimiento de la cueva de Urratxa III (Orozko, Bizkaia). Universidad de Deusto-Deustuko Unibertsitatea. Bilbao.

Ormazábal, A. 2008: "La industria lítica de Portugain en su contexto". En I. Barandiarán y A. Cava (eds.): Cazadores y tallistas en el abrigo de Portugain: una ocupación de Urbasa durante el Tardiglaciar. Colección Barandiarán 12, Fundación J. M. de Barandiarán. Ataún: 241-266.

Soto Barreiro, M. J. 2003: Cronología radiométrica, ecología y clima del Paleolítico cantábrico. Monografías Museo Nacional y Centro de Investigaciones de Altamira 19, Ministerio de Educación, Cultura y Deporte. Madrid.
Utrilla, P. 1982-1983: "El yacimiento de la Cueva de Abauntz (Arraiz, Navarra)". Trabajos de Arqueología de Navarra 3: 203-345.

Utrilla, P.; Montes, L.; Mazo, C.; Alday, A.; Rodanés, J. M.; Blasco, M. F.; Domingo, R. y Bea, M. 2010: "El Paleolítico superior en la cuenca del Ebro a principios del siglo XXI. Revisión y novedades". En X. Mangado (ed.): Homenaje al profesor Javier Fortea. Monografies Seminari d'Estudis i Recerques Prehistòriques 8, Universitat de Barcelona. Barcelona: 23-62.

Weninger, B.; Jöris, O. y Danzeglocke, U. 2007: CalPal-2007. Cologne Radiocarbon Calibration \& Palaeoclimate Research Package. http://www.CalPal. de/ (consulta 2012-III-12). 